\title{
A Verdade em Martin Heidegger e Walter Benjamin
}

Eduardo Triandopolis ${ }^{1} 1$

\section{RESUMO}

Alemães e contemporâneos, Benjamin e Heidegger, não se conheceram, e não houve possibilidade de um debate ou troca de ideias entre eles. Não há indícios de que Heidegger tenha esboçado alguma crítica à obra de Benjamin. Por outro lado, são conhecidos os comentários de Benjamin sobre os primeiros escritos de Heidegger, o "Conceito de Tempo na Ciência da História" e "A Doutrina das Categorias e do Significado em Duns Scotus", ambos de 1916. Possivelmente, a crítica sistemática aos primeiros escritos de Heidegger empreendida por Benjamin foi de grande importância para a conclusão da Obra "Origem do Drama Barroco Alemão". Nesse sentido, tentaremos, a partir do conceito da tradição, como elemento divergente central da crítica de Benjamin a Heidegger, estabelecer alguns paralelos entre os escritos posteriores dos dois filósofos, escritos estes considerados suas obras-primas: "Origem do Drama Barroco Alemão" e "Ser e Tempo".

Palavras-chave: Verdade, Tradição, Apresentação, Mostração, Origem

\section{ABSTRAC}

Benjamin and Heidegger were german and contemporaries, but they never met each other therefore, there was no possibility of a debate nor exchange of ideas between them. There is no evidence Heidegger has ever critized Benjamin's work. On the other hand, Benjamin's comments on Heidegger's early writings, "The Concept of Time in the Science of History" and "The Theory of Categories and Meaning in Duns Scotus", both written in 1916, are widely known. Perhaps the systematic critique of Heidegger's early writings undertaken by Benjamin was of great importance for completing the work "The Origin of German Tragic Drama". In this way, we will try to establish some parallels between the later writings of these two philosophers: "The Origin of German Tragic Drama" and "Being and Time", their masterpieces, through the concept of tradition as central part of Benjamin's critique to Heidegger.

Key words: Truth, Tradition, Presentation, Representation, Origin.

\footnotetext{
${ }^{1}$ Eduardo Jorge Oliveira Triandopolis é Doutor em Filosofia pela Freie Universität Berlin (1996) e PósDoutor pelo Centro de Antropologia Histórica da Freie Universität Berlin (2002). Atualmente é professor Adjunto da Universidade Estadual do Ceará (UECE) e líder do Grupo de Pesquisa Metafísica e Estética do diretório do CNPq.
} 
Esboçado em 1916 e redigido em 1925, a obra "Origem do Drama Barroco Alemão" pode ser considerada uma das mais importantes de Walter Benjamim. Na mesma época, em 1927, surgiria também "Ser e Tempo" de Martin Heidegger, considerado um dos mais importantes filósofos do século 20.

Alemães e contemporâneos, Benjamim e Heiddeger, não se conheceram, e não houve possibilidade de um debate ou troca de idéias entre eles. Não há indícios de que Heiddeger tenha esboçado alguma crítica à obra de Benjamim. Por outro lado, são conhecidos os comentários de Benjamim sobre os primeiros escritos de Heiddeger. Dois desses escritos seriam marcantes para a crítica benjaminiana: O Tratado Der Zeitbegriff in der Geschichtswissenschaft (O Conceito de Tempo na Ciência da História) de 1916 e a tese de livre docência Die Kategorien-und Bedeutungslehre des Duns Scotus

(A Doutrina das Categorias e do Significado em Duns Scotus) também de 1916. Nestes escritos, de forte impressão neokantiana, o discurso gira em torno da distinção entre as esferas do lógico e do mundo dos fatos. Nesse contexto, a primeira esfera seria marcada pela imutabilidade e a segunda pela mudança e pelo tempo. Aqui, o sujeito vai captar os significados temporalmente, mas na sua validade não ameaçada pela mudança. Assim, a validade dos significados elimina por definição o aspecto temporal próprio ao mundo do sujeito. A esfera lógica é, pois, irredutível à esfera psíquica. No entanto, devemos ressaltar no tratado sobre as categorias que para Heiddeger o "Espírito vivente, enquanto tal, é essencialmente espírito histórico no sentido mais amplo da palavra. ${ }^{2} \mathrm{~A}$ filosofia, ao indagar pela realidade do lógico, deverá sempre ser conduzida a um contexto translógico. Diria Heiddeger:

\footnotetext{
"De forma alguma podemos ver a lógica e seus problemas na verdadeira luz se o contexto no qual ela é interpretada, não se tornar translógico. A Filosofia não pode, a longo prazo, prescindir da óptica que lhe é mais própria, a metafísica. Para a teoria da verdade, isto significa a tarefa de uma interpretação metafísico-teleológica definitiva da consciência.”3
}

\footnotetext{
${ }^{2}$ Der lebendige Geist ist als solcher wesensmäßig historischer Geist im weitesten Sinne des Wortes. Heidegger, Martin - Die Kategorien- und Bedeutungslehre des Duns Scotus. Frankfurt am Main, Vittorio Klostermann. 1972, p. 349.

3 Heidegger, Martin - Die Kategorien- und Bedeutungslehre des Duns Scotus. Frankfurt am Main, Vittorio Klostermann. 1972 , p. 348.
} 
Foi nessa fase, marcada pelo neokantismo, que Heiddeger, de forma incipiente, desenvolveu as temáticas da tradição e da temporalidade que lhe conduziram até a composição aprofundada da Obra "Ser e Tempo". Possivelmente, a crítica sistemática aos primeiros escritos de Heidegger empreendida por Benjamim foi de grande importância para a conclusão da Obra "Origem do Drama Barroco Alemão". Nesse sentido, tentaremos, a partir do conceito da tradição, como elemento divergente central da crítica benjaminiana aos primeiros escritos de Heidegger, estabelecer alguns paralelos entre os escritos posteriores dos dois filósofos, escritos estes, considerados suas obras-primas "Ser e Tempo" e "Origem do Drama Barroco Alemão".

Inicialmente gostaria de fazer algumas observações no tocante à palavra origem (Ursprung) no título da obra benjaminiana e ao significado atribuído por Heidegger em "Ser e Tempo". A Crítica de Benjamim aponta para um conceito de tempo desenvolvido por Heidegger no seu escrito "O Conceito de Tempo na Ciência da História" de 1916 onde ele desenvolve, por meio de uma contraposição aos parâmetros de tempo da física, um conceito de tempo histórico. As análises de Heidegger acerca da história, da tradição e da origem só serão de fato elucidadas em "Ser e Tempo". Mas, já no escrito sobre a história, fica clara a função paradoxal do tempo tanto na presentificação do passado como também na sua exclusão tornando-o diverso do presente. Ao reconhecer a heterogeneidade temporal entre passado e presente, Heidegger identifica a ambigüidade da tradição como mascaramento e revelação da verdade.

A experiência autêntica no tempo só será mencionada em "Ser e Tempo"; não mais como um problema metodológico, marca do escrito sobre a história, mas como um problema ontológico fundado em uma reformulação da questão do ser. A exposição ontológico-existencial do problema da história, passa pelo antigo e suas possibilidades. Assim, para Heidegger, a questão do ser só atingirá seu lugar concreto na repetição da tradição. Uma ontologia fundamental é reiteração da tradição enquanto desconstrução (destruição) da mesma. Esse é o sentido da recolocação da questão do ser, que em "Ser e Tempo" será uma indagação pelo ser do ente. Esse ente, no entanto, encontra-se dado na tradição como aquele cujo ser só pode ser compreendido no ver, no seu ser diante do olhar, como mera presença ou presencialidade; a partir de um determinado modo temporal, o presente. A prescrição pela tradição do ser e do tempo como presença será contestada na própria tradição. A ontologia fundamental é, pois, uma ontologia da 
origem (Ursprung). Uma interpretação originária é fundamental na explicitação dos aspectos derivados da origem e segundo Heidegger, nos "Contributos à Filosofia":

\footnotetext{
"Se questionamos mais originalmente, isto nunca garantirá uma resposta mais certa, mas, ao contrário, apenas uma questionabilidade mais elevada acerca da essência da verdade; e precisamos desta questionabilidade, pois sem ela a verdade permanece indiferente." 4
}

Para Heidegger, Ursprung (Origem) e Anfang (Começo) são palavras correlatas. O pensamento primordial (anfängliche) é aquele que remete, envia (überliefern) para trás a questão acerca do ser, em direção à origem (Ursprung), ao começo (Anfang) da filosofia. Nesse contexto, Heiddeger vislumbra a possibilidade da tradição ser um veículo apropriado para a busca da autenticidade originária (ursprunglichelanfängliche). Essa parece uma idéia difícil de Benjamim admitir, pois para ele um tempo histórico só será autêntico e redimido na interrupção da temporalidade histórica compreendida como marcha de catástrofe, por meio da ação política no princípio do agora (Jetztzeit) messiânico. Diferente de Heidegger, para quem passado pode ser promovido ou combatido no presente, sendo possível uma redenção no tempo histórico, para Benjamin, só haverá redenção do tempo histórico, e assim, todos os eventos no tempo só podem ser inautênticos e vazios de significado. Para Benjamin, promover a tradição é destruir e dispersar.

Segundo Heidegger, um Ursprung (Origem) é um Sprung (Salto) radical, um salto antecipante que anuncia o mistério de todo o começo como momento singular de criação. Para Benjamin, a origem (Ursprung) nasce do vir-a-ser e da extinção, é um salto em direção ao novo. Ele não pode mais se confundir com a origem (gênese). Ursprung é agora entspringen, saltar como uma fuga do objeto histórico, do fluxo da história contínua. Essa fuga anuncia uma história descontínua sem a gênese e o seu correlato vir-a-ser causal.

A exposição benjaminiana ainda mantém o caráter enigmático na sua introdução epistemológica à "Origem do Drama Barroco Alemão" no tocante ao seu conceito de

\footnotetext{
${ }^{4}$ Heidegger, Martin - Beiträge zur Philosophie (Von Ereignis) Frankfurt am Main, Vittorio Klostermann. 2003, p. 372.
} 
Darstellung (apresentação/exposição). Tentaremos aqui, a partir de suas interpretações acerca da idéia, estabelecer alguns paralelos com o conceito de Vorstellung (representação) desenvolvido em Heiddeger na sua "Teoria Platônica da Verdade".

O Conceito de Darstellung (apresentação/exposição) enquanto escrita filosófica em Benjamin, não tem e nem pode ter o sentido tradicional de representação mental de objetos externos, além do sujeito pensante. O sentido da palavra é o da exposição/ordenação enquanto valor retórico que visa à contemplação da verdade e o resguardo da dimensão estética do saber. A Darstellung der Wahrheit (exposição da verdade) aponta para a dimensão da percepção sensível via alusão e referência, e com isso, para um duplo sentido: a filosofia deve apresentar e expor a verdade, e esta só se essencializa na exposição de si mesma. A verdade não tem medida comum com o dizer, e assim, jamais será conhecida na filosofia enquanto Vorstellung (representação), pois sempre se subtrairá à expressão.

Para fundamentar sua tese, Benjamin recorre à teoria das idéias de Platão para contrapor-se à "incoerência no método da teoria do conhecimento científico que parte de pretensos postulados filosóficos". 5 Assim, para Benjamin, a salvação dos fenômenos encontra-se nos seus elementos, no reino das idéias e na unidade autêntica da verdade. ${ }^{6}$ A falsa unidade fenomênica é depurada em uma submissão ao conceito como um processo abstrativo possibilitador da experiência da verdade. A dissolução das coisas em conceitos não tem mais aquela conotação destrutiva, tão anunciada por adorno na "Minima Moralia". O conceito agora tem um papel mediador (Vermittlerrolle) de apresentação/exposição emprestando aos fenômenos participação no ser das idéias. ${ }^{7}$ Para Benjamim, as idéias passam a ser o "ordenamento objetivo virtual dos fenômenos". 8 Como bem observa Rouanet na sua apresentação à obra de Benjamin "Origem do Drama Barroco Alemão":

“o 'platonismo' de Benjamin acaba revelando-se, assim, um ‘objetivismo' radical. É por fidelidade às coisas que ele precisa do mundo das idéias. Sem elas, os fenômenos não teriam 'uma interpretação objetiva', o que os condenaria à mudez e à tristeza, e não poderiam ser salvos, pois se

\footnotetext{
${ }^{5}$ Ursprung des deutschen Trauerspiels. Suhrkamp Verlag. Frankfurt am Main. 1991, p. 213.

6 Ibidem, p. 213.

${ }^{7}$ Ibidem, p. 214.

${ }^{8}$ Ibidem, p. 214.
} 
dissolveriam, seja no conceito, seja numa 'visão' subjetiva, na qual não há lugar para o objeto." 9

$\mathrm{Na}$ "Teoria Platônica da Verdade", Heidegger vai ressaltar o sentido dado por Platão à verdade na relação entre visualidade (Aussicht) e visibilidade (Sichtbarkeit) entre $\varepsilon \imath \delta o \zeta$ e $1 \delta \varepsilon \alpha$. Para Platão, segundo Heidegger:

"a "idéia" é o aspecto que empresta visibilidade àquilo que se mostra. A $1 \delta \varepsilon \alpha$ é o puro brilhar no sentido da expressão "o sol brilha". A “idéia” não deixa "brilhar" ainda outra coisa (por trás de si), ela própria é o que resplandece, a única coisa que reside no resplandecer de si mesma. A $1 \delta \varepsilon \alpha$ é o resplandecente. A essência da idéia reside no caráter de luminosidade e visualidade." 10

Assim, segundo Heidegger, verdade em Platão é aquilo que é acessível por meio da luminosidade da idéia. Todavia, o acesso proporcionado por um ver só é possível se esse for sonnenhaft, se estiver em conformidade com o luzir do sol, fonte da luz e da visibilidade do que é visto. ${ }^{11}$ Assim, para Platão, a imagem do sol como idéia do bem

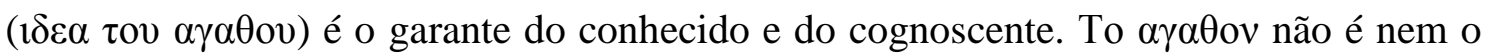
bem moral nem a representação subjetiva no sentido moderno. Para o grego, diria Heidegger, "o bem significa aquilo que se presta para alguma coisa ou que torna algo prestável para alguma coisa." ${ }^{12}$ Se a idéia serve para que algo apareça naquilo que é e dessa maneira vigore, aquilo que faz com que uma idéia se preste para tal é a idéia suprema que possibilita a visualidade e a visibilidade de tudo.

Assim, para Platão, a verdade $(\alpha \lambda \eta \theta \varepsilon ı \alpha)$ encontra-se sob o jugo da idéia ( $1 \delta \varepsilon \alpha)$ pois esta é a senhora que permite o desvelamento como ele próprio afirma na Politéia 517 c, 4. Nessa passagem, Heidegger ressalta um deslocamento da essência da verdade, desenvolvida em si própria a partir do referencial negativo da $\lambda \eta \theta \eta$, para a essência da $1 \delta \varepsilon \alpha$ no seu referencial de visualização enquanto Vorstellung (representação). Isso

\footnotetext{
9 Rouanet, Sérgio Paulo - Apresentação à obra “Origem do Drama Barroco Alemão” de Walter Benjamin. São Paulo. Brasiliense. 1984, p. 15.

${ }^{10}$ Heidegger, Martin - Platons Lehre Von der Wahrheit. Wegmarken. Frankfurt am Main. Klostermann, 2004, p. 225.

11 Ibidem, p. 226.

12 Ibidem, p. 227.
} 
ocorre por meio da mutação da verdade $(\alpha \lambda \eta \theta \varepsilon l \alpha)$ em luz $(\varphi \omega \varsigma)$ e consequentemente por meio da diluição da questão acerca do encobrimento e da ocultação. A positivação da $\alpha \lambda \eta \theta \varepsilon ı \alpha$ torna tudo acessível. Contudo, a pergunta pela sua origem abissal se perde na própria profundidade. Se desde Platão $\alpha \lambda \eta \theta \varepsilon ı \alpha$ é acesso, ao lado do ente ela torna-se revelação, permanecendo desocultamento do ente, mas jamais do ser. ${ }^{13}$ Nesse sentido, o

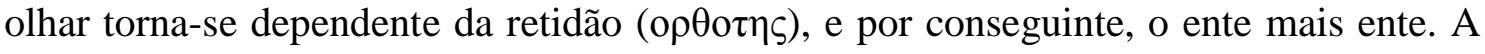
partir da adequação do ver $(1 \delta \varepsilon ı v)$ à ideia $(1 \delta \varepsilon \alpha)$ dá-se a concordância $(o \mu o ı \omega \sigma ı \varsigma)$ do conhecer com a coisa. Aqui teríamos a supremacia da verdade como correção na retidão do ver e do dizer.

Nos parágrafos 33 e 44 de "Ser e Tempo" Heidegger indaga acerca da validade dessa concepção ou pelo menos do seu caráter primaz. Também nos escritos sobre Nietzsche, ressalta a afinidade entre a Vorstellung, como teoria representacional da percepção e a teoria da verdade como correspondência desde sua origem platônica. Sua intenção é questionar o fundamento da verdade na relação intelecto e coisa, o que está implícito nessa relação. Esta concepção tradicional de verdade é atacada de diversos modos por Heidegger partindo da tese de que "a verdade originária não tem sua morada original na proposição. ${ }^{14}$

Com a fenomenologia, Heidegger questionará a preponderância judicativa do $\operatorname{logos}\left(\lambda \operatorname{\gamma o}_{0 \varsigma}\right)$. Na investigação etimológica da palavra fenômeno, ele ressalta o sentido grego de paıvó $\mu \varepsilon v o v$ derivado do verbo $\varphi \alpha \imath \varepsilon \varepsilon \sigma \tau \alpha \imath$ (mostrar-se, aquilo que se mostra a si mesmo). Pertence à raiz dessa palavra o $\varphi \alpha$ ligado à $\varphi \omega s$, luz e claridade. Heidegger mantém assim, como significado dos fenômenos, aquela totalidade que vem à luz do dia e que os gregos denominavam $\tau \alpha$ ov $\tau \alpha$, os entes. Esses entes podem mostrar-se de diversas maneiras, até mesmo como aquilo que eles não são, ${ }^{15}$ e assim, fenômeno é também aparência (Schein). Heidegger avança nas determinações terminológicas envolvendo na discussão a palavra manifestação (Erscheinung). Essa manifestação é um enunciar algo que não se mostra, entendendo com isso, o manifestar-se como o não mostrar-se. Aqui está pressuposto o conceito de fenômeno, mesmo que de forma velada. Aqui, o fenômeno é um modo privilegiado, enquanto a manifestação só indica uma

\footnotetext{
${ }^{13}$ Heidegger, Martin. Beitraege zur Philosophie (Vom Ereignis). Frankfurt am Main: Klostermann, 2003, p. 332.

${ }^{14}$ Heidegger, Martin. Sein und Zeit. Tuebingen. Max Niemeyer Verlag. 2006, p. 154. Cf. Vom Wesen der Wahrheit. Wegmarken. Frankfurt am Main: Klostermann, 2004. P. 185.

${ }^{15}$ HEIDEGGER, Martin. Sein und Zeit. Tuebingen: Max Niemeyer Verlag. 2006. P. 29.
} 
remissão alusiva cuja função só é possível na pressuposição do fenômeno como aquilo que se mostra em si mesmo.

No entanto, para Heidegger, é preciso ainda compreender o conceito de fenômeno de modo fenomenológico, e isso significa uma determinação mais precisa daquilo que se mostra em si mesmo. Para isso, faz-se necessário uma investigação da palavra logos ( $\lambda$ ó ${ }_{0} \varsigma$ ) no seu sentido proposicional ou judicativo. Em Aristóteles,

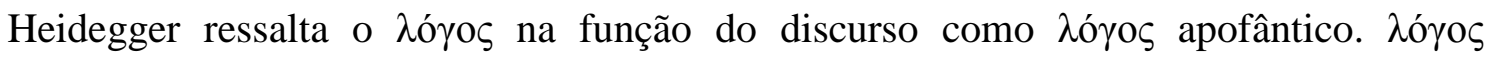
enquanto discurso ( $\alpha \pi$ ó $\alpha v \sigma 1 \zeta)$ torna acessível aos outros entes aquilo sobre o que discorre. O deixar e fazer ver do discurso articula-se concretamente na fala ( $\varphi \omega \vee \eta)$

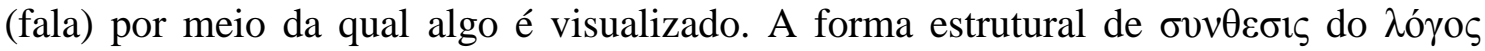
reside no deixar ver analógico das coisas. Esse significado apofântico indica o deixar e fazer ver algo na contigüidade. E porque o $\lambda$ ó ${ }$ os é um deixar e fazer ver é que ele pode ser verdadeiro ou falso. Assim como o ser verdadeiro deixa e faz ver o ente como algo desvelado $(\alpha \lambda \eta \theta \varepsilon \dot{\varepsilon} \varsigma)$ também o ser falso ( $\psi \varepsilon v ́ \delta \varepsilon \sigma \theta \alpha$ ) deixa e faz ver uma coisa como outra a pondo como algo que ela não é. Com isso, Heidegger afirma:

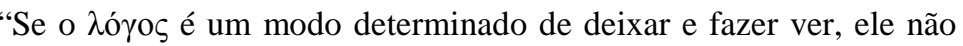
poderá ser apontado como o lugar primário da verdade... Em sentido grego o que é verdadeiro de modo ainda mais originário do que o $\lambda$ ó $\gamma$ o s é a $\alpha \iota \sigma \theta \eta \sigma ı \varsigma$ a simples percepção sensível de alguma coisa." 16

No entanto, o lugar da verdade não se encontra mais na própria coisa, mas na retidão do olhar humano para ela. A despeito da coisa possuir o ser e trazer consigo o desencobrimento, o padrão não é mais o da $\alpha \lambda \eta \theta \varepsilon ı \alpha$, no sentido dado por Heidegger,

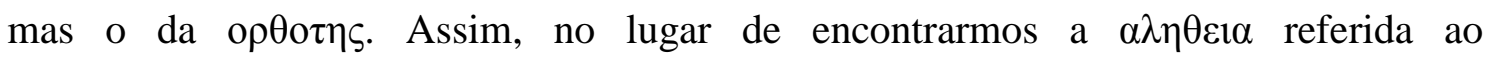
encobrimento, encontraremos uma $\alpha \lambda \eta \theta \varepsilon 1 \alpha$ contraposta ao $\psi \varepsilon v \delta o \zeta$, entendido como o falso, como o não reto.

O enunciar judicativo como lugar da verdade encontra-se desde então na metafísica clássica, é sistematizado na escolástica por Tomás de Aquino e fortalecido na

\footnotetext{
${ }^{16}$ HEIDEGGER, Martin. Sein und Zeit. Tuebingen: Max Niemeyer Verlag. 2006. P. 33.
} 
metafísica moderna por Descartes. Para Aquino ${ }^{17}$ "a verdade encontra-se propriamente no intelecto humano ou divino". Para Descartes "18 "verdade ou falsidade, em sentido próprio, não podem estar em nenhum outro lugar a não ser no intelecto".

Para Heidegger, o ser do ente visualizado nas idéias desde Platão inaugura o pensamento metafísico como um olhar ascendente em direção às ideias e à ideia mais elevada como causa primeira do surgir de todo ente. Essa causa é $\tau$ o $\alpha \gamma \alpha \theta$ ov, o bem, mas também é $\tau$ o $\theta \varepsilon ı v$, o divino. Pensar o ser do ente é metafísica e teologia. ${ }^{19}$

A percepção do ser como aquilo que encobre e protege será esquecida. Ao identificar $\alpha \lambda \eta \theta \varepsilon 1 \alpha$ à $1 \delta \varepsilon \alpha$, Platão ressalta o aspecto do simplesmente dado associando-o à luz. $\mathrm{O}$ ente torna-se então, aquilo que é achado e pronto; o objetivamente dado. $\mathrm{O}$ homem disporá esse disponível, convertendo o ente em objeto, seja para contemplação, seja para a ação produtiva. O aparecer, no grande sentido da epifania de um mundo, torna-se visibilidade ostentável de coisas objetivamente dadas. ${ }^{20}$

Assim como Heidegger, Benjamim também vai recorrer aos conceitos platônicos para tentar amenizar os transtornos da exposição da verdade na tradição metafísica. Mas sua análise é estética e emerge da relação entre verdade e beleza na erótica platônica. Não obstante o distanciamento da sua análise de uma concepção ontológica hierárquica que vai do belo ôntico ao belo inteligível, Benjamin permanece na trilha de Platão ao fazer justiça à beleza elevando a verdade como o seu garante ontológico. No entanto, a beleza não estará mais restrita à esfera do brilho (Schein) e da aparência (Erscheinung). Ela pertence ao inteligível como mostração, apresentação e exposição da verdade; surge fugaz como imagem dialética, em uma iluminação profana do pensamento.

\footnotetext{
${ }^{17}$ Aquino, Tomás - Questões Disputadas "Sobre a Verdade". I - 4, solução. Cf. Verdade e Conhecimento. São Paulo-SP: Martins Fontes. 2002, p. 181. Cf. Heidegger, Martin. Platons Lehre von der Wahrheit. Wegmarken. Frankfurt am Main: Klostermann, 2004, p. 244.

${ }^{18}$ Heidegger, Martin - Platons Lehre von der Wahrheit. Wegmarken. Frankfurt am Main. Klostermann, 2004, p 245.

${ }^{19}$ Ibidem, p. 235-236.

${ }^{20}$ Ibidem, p. 90.
} 